Canadian

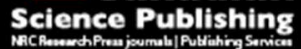

Canadian Journal of Forest Research Revue canadienne de recherche forestière

\title{
Seed production of sugar maple and American beech in northern hardwood forests, New Hampshire, USA.
}

\begin{tabular}{|r|l|}
\hline Journal: & Canadian Journal of Forest Research \\
\hline Manuscript ID & cjfr-2017-0096.R1 \\
\hline Manuscript Type: & Note \\
\hline Date Submitted by the Author: & 07-Apr-2017 \\
\hline Complete List of Authors: & $\begin{array}{l}\text { Cleavitt, Natalie; Cornell University } \\
\text { Fahey, Timothy; Cornell University, Natural Resources }\end{array}$ \\
\hline $\begin{array}{r}\text { Keyword: } \\
\text { Konsideration in a Special } \\
\text { Issue? : }\end{array}$ & masting, $\Delta$ T model, Acer saccharum, Fagus grandifolia, temperature cue \\
\hline & \\
\hline
\end{tabular}


2 Seed production of sugar maple and American beech in northern hardwood forests,

3 New Hampshire, USA.

4

5 Natalie L. Cleavitt; Dept. of Natural Resources, Fernow Hall, Cornell University, Ithaca, NY

$6 \quad 14853$

7 e-mail: nlc4@cornell.edu

8

9 Timothy J. Fahey; Dept. of Natural Resources, Fernow Hall, Cornell University, Ithaca, NY $10 \quad 14853$

11 e-mail: tjf4@cornell.edu

12

13 Author for correspondence:

14 Natalie L. Cleavitt

15 e-mail: nlc4@cornell.edu

16 Phone: 603-960-2519

17 Mailing address: 55 Perch Pond Road, Holderness, NH 03245

18 
Abstract. Mast seeding is the synchronous production of large seed crops in plant

21 populations and for many tree species is known to be determined by the interaction between

22 weather cues and internal plant resources. We use a 24-year record of seed fall for sugar maple

23 and American beech across a northern hardwood forest landscape to quantify their masting

24 patterns and explore the relationship between mast years, resources and weather cues,

25 particularly the difference between summer temperatures in the two years prior to the seed fall

26 year $(\Delta T)$. We found clear evidence of masting in these species and mast years were often

27 coincident in the two species; masting was best predicted by $\Delta \mathrm{T}$ or $\Delta \mathrm{T}$ plus previous-year seed

28 fall. We saw no evidence for correspondence of masting in these trees to precipitation cues. A

29 soil calcium addition modified elevation effects on seed production. Clarification of the

30 controls on mast seeding for these important tree species will aid in predicting such resources as

31 mast for wildlife and maple sugar production in northern hardwood forests.

33 Keywords: masting, $\Delta \mathrm{T}$ model, Acer saccharum, Fagus grandifolia, temperature cue 


\section{Introduction}

Masting is the synchronous and highly variable seed production among years by populations of plant species and is common among wind-pollinated trees. Selection pressure for masting is thought to involve such functional roles as predator satiation (Janzen 1971) and enhanced dispersal (Jansen et al. 2004). Weather cues clearly play a key role as proximate environmental cues for masting (Kelly et al. 2013), but internal plant resource dynamics also have been shown to influence the timing and magnitude of mast events (Pearse et al. 2016). In addition to effects on tree reproduction, masting has important implications for animal populations and trophic dynamics in forests (Ostfeld and Keesing 2000).

Northern hardwood forests dominated by sugar maple (Acer saccharum Marsh.; ACSA) and American beech (Fagus grandifolia Ehrh.; FAGR) are widely distributed across northeastern North America, and both species are regarded as putative masting tree species (sensu Kelly 1994). Although studies from the region provide a record of high seed years for these species, affording a nearly 50 year signal (Table S1), the relationships between masting by these two species have not been explored quantitatively, and the cues and internal controls of masting are not entirely clear. Masting by American beech is particularly important for wildlife population dynamics in this region (Bergeron et al. 2011; Jakubas et al. 2005) in the absence of other "hard" mast species (e.g., oaks), and variation in seed production in northern hardwood forests has wide and interacting effects on trophic relations (Bergeron et al. 2011; Jensen et al. 2012) and tree recruitment dynamics (Cleavitt et al. 2008; Cleavitt et al. 2011).

In general, weather cues exert primary control over masting in perennial plants, and Kelly et al. (2013) presented a strong case for a $\Delta \mathrm{T}$ model in which the difference in temperature between the two previous years regulates subsequent-year masting in a wide suite of plants. 
57 Additional internal cues related to plant resource balance (e.g., carbon, nitrogen (N), phosphorus

58 (P)) have been shown to exert a complementary influence on masting (Crone and Rapp 2014,

59 Pearse et al. 2016); for example, negative correlations between seed production in the current

60 year to that in the previous year have been reported (Kelly 1994). Variation in seed production

61 for sugar maple and American beech has received limited analysis in relation to weather cues,

62 and the $\Delta \mathrm{T}$ model has not been tested for these tree species. Seed production for FAGR has been

63 related to midsummer water stress in the year preceding the seed year, as well as to July

64 temperature two years preceding the seed year (Piovesan and Adams 2001). The role of drought

65 in signaling mast years for ACSA also has been suggested based on correlations between the

66 Palmer Drought Severity Index (PDSI) and high seed years in Pennsylvania (Long et al. 1997,

67 2011). The relative predictive power of standard meterological variables (e.g., preceding year

68 conditions) versus differential variables (e.g., $\Delta \mathrm{T}$ model) for masting has implications for the

69 sensitivity of seed production to climate change (Kelly et al. 2013; Koenig et al. 2016).

70

The possible role of resource balance influencing masting in these species also has been

71 indicated. In particular, negative correlations have been observed between current- and previous-

72 year seed production of FAGR in Michigan (Piovesan and Adams 2001), and maple sugar

73 production in Vermont was lower in the year following mast years of ACSA (Rapp and Crone

74 2015). The magnitude and frequency of masting also may be reduced in the stressful

75 environment near a species' range limits (Kelly and Sork 2002) suggestive of resource limitation.

76 The role of nutrient (N, P) limitation in masting has been indicated by nutrient depletion the year

77 after masting occurs (Pearse et al. 2016), and liming of severely calcium (Ca)-deficient sites

78 resulted in increased seed production of ACSA in Pennsylvania (Long et al. 2011) and New 
79 Hampshire (Halman et al. 2013). Calcium addition apparently influenced seed production

80 through increased flower production on in both of these studies.

We use a 24-year record of seed fall for ACSA and FAGR collected at Hubbard Brook

82 Experimental Forest (HBEF) to address several questions. At the forest level: 1) Does masting

83 occur in these two tree species and are their mast years coincident? 2) Can we predict seed

84 production in these two species from exogenous (e.g., temperature, precipitation) and endogenous (e.g., negative correlation) cues? At the site level: 3) How do parameters of masting sensitive species?

\section{Materials and Methods} and Bormann (1995). The climate is humid continental with short, cool summers and long, cold

97 winters. Annual precipitation averages $140 \mathrm{~cm}$; mean annual temperature is $5.5^{\circ} \mathrm{C}$; and daily temperatures average from $-8.5^{\circ} \mathrm{C}$ in January to $18.8^{\circ} \mathrm{C}$ in July (Bailey et al. 2003). 
102 103

zones: 500m (500-525 m); 600m, (600-625 m); and 700m, (700-725 m) within three study sites, two reference sites and one Ca treated site (Table 1). The calcium silicate mineral, wollastonite, was applied to Watershed 1 (hereafter referred to as "CAL') by helicopter in Otober 1999 with a uniform delivery rate of $1028 \mathrm{~kg} \mathrm{Ca} \mathrm{ha}^{-1}$ (Peters et al. 2004). This treatment was explicitly designed to replace the $\mathrm{Ca}$ that was lost from the Hubbard Brook forest as a result of human activity during the $20^{\text {th }}$ century and thereby to evaluate the likely effects of anthropogenic soil Ca depletion on forest ecosystem dynamics (Battles et al. 2014). The pool of exchangeable Ca increased significantly after treatment, peaking in the O horizons by 2002 and in the upper mineral soil by 2006 (Johnson et al. 2014).

In each year, all seeds and leaves were collected from the baskets, sorted, and counted three times a year: early May, late August and after leaf-off in early November. All collections were pooled by year for analysis. To standardize for differences in species abundance among plots we also express seed fall per unit of leaf fall for each species (i.e., relative seed production) for between plot tests.

We followed existing conventions to define masting species (Kelly 1994) and mast years (LaMontagne and Boutin 2009). For the forest-level analyses we pooled all reference site data from 1994, 1995, 1997-2016 to calculate the long-term mean and annual standard deviation (ASD) of seedfall (seeds per $\mathrm{m}^{-2}$ ). Pooling the data reduced the occurrence of zero counts and matched the scale of available meteorological data (see below). In addition, this forest-level approach should make for a more robust comparison to mast years reported in other studies (Table S1). We examined the coefficient of variation (CV; long-term standard deviation divided by the mean) for the two species and the annual deviate from the long-term mean; species with CV $>1$ are defined as masting species (Kelly 1994). Mast years were defined as years when seed 
125 production is greater than the absolute value of the minimum standardized deviate (LaMontagne 126 and Boutin 2009). To test for concordance in seed production for ACSA and FAGR, we looked 127 for shared mast years and Spearman rank correlations (LaMontagne and Boutin 2007).

We used a 19-year (1998-2016) seed fall record for reference sites together with temperature and precipitation records from the HBEF (http://www.hubbardbrook.org/data/ 130 dataset_search.php) to explore relationships between weather cues and seed production. 131 Temperature data were mean monthly temperatures $\left({ }^{\circ} \mathrm{C}\right)$ averaged for two stations (stations 1 132 and 6, which span the elevation range of the seed collectors; Bailey et al. 2003), The 133 precipitation data $(\mathrm{mm})$ were growing season (15 April - 15 November) totals for each year from 134 the mean of three stations (stations 9-11; nearly coincident with our collection sites; Bailey et al. 135 2003). Therefore, the seedfall and metrological data sets covered similar landscape variability. 139 summers (sum of mean monthly temperatures for June-August) to predict seed production in the 140 third year. We also evaluated possible effects of precipitation variation (Piovesan and Adams 141 2001), and summer temperature two years previous (2T model in Kelley et al. (2013)). Finally, 142 we evaluated the possible effects of previous-year seed production as evidence of resource 143 balance controls on seed production (Kelly 1994). Generalized Linear Models (GLMs) analyzing 144 the logarithm of seeds $\mathrm{m}^{-2}$ were run in JMP Pro 11 for Windows (SAS Institute Inc., Cary, NC) 145 and compared using the reduction in model deviance and bias corrected Akaike's Information 146 Criterion $\left(\mathrm{AIC}_{\mathrm{c}}\right)$. 
At the site-level ( $\mathrm{N}=9$; Table 1), we examined the synchrony of seed production across

148

sites for both species using Spearman rank correlations (LaMontagne and Boutin 2007) and the ASD (described above) to delineate mast years for comparison of masting frequency. To test for differences in variability, we calculated site-level $\mathrm{CV}\left(\mathrm{CV}_{\mathrm{s}}\right)$ using the full data set for each site (Table 1; 19-24yrs). To compare the magnitude of seed production between sites (including Ca treatment) and elevations, we used the balanced data set for 19 years of seed fall (1998-2016). For these analyses, relative seed production (seeds leaf ${ }^{-1}$ ) was more appropriate as these values account for differences in species abundance among the sites. In a mixed model analyzing the logarithm of relative seed production, year was a random factor and site and elevation with their interaction were fixed factors to test for site and elevation differences. Significance tests were followed by Tukey-Kramer HSD multiple comparisons.

\section{Results}

During the 19-year record, both ACSA and FAGR had a CV $>1$ and five mast years with four of these years coincident for both species (Fig. 1). The synchronicity of seed production between the species was highly significant for both reference sites, but higher at REF1 (Spearman corr. $=0.673 ; \mathrm{p}<0.0001)$ than at REF $2(0.3349 ; \mathrm{p}=0.0060)$.

The best overall model for predicting seed fall in ACSA was the $\Delta \mathrm{T}$ model and for FAGR the best model included both $\Delta \mathrm{T}$ and previous year's seed fall (Table 2; Fig. 2). The $\Delta \mathrm{T}$ model was a better overall predictor than the standard weather variables (Table 2). Summer temperature in year ${ }^{-2}$ was a significant predictor for both species, and neither species was significantly related to the other precipitation or temperature variables tested, including differential precipitation (Table 2). The best models predicted higher seed fall for ACSA in 2008 and 2013 and for FAGR in 2012 than was actually observed (Fig. 2). 
171 FAGR (Table 3). Within sites, the 700m elevation site had the lowest correlation to seed

172 production in other sites, particularly at REF2 for both species and CAL for FAGR (Table 3).

173 Frequency of mast years was not significantly different among elevation zones (Contingency $\mathrm{X}^{2}$ :

$174 \mathrm{ACSA}=1.66 ; \mathrm{p}=0.437 ; \mathrm{FAGR}=2.42 ; \mathrm{p}=0.300)$ though they occurred more often in low 175 elevation sites for all areas except at CAL for ACSA.

177 high elevation site (Table 3). The $\mathrm{CV}_{\mathrm{s}}$ values tended to be higher at high elevation sites for 178 ACSA as years with moderate seed production were lacking (Table 3; Fig. S1). In contrast, the $179 \mathrm{CV}_{\mathrm{s}}$ for FAGR was lower at high elevation sites with more years of moderate seed production 180 (Table 3; Fig. S1). There was no evidence for increased seed fall of ACSA in the CAL site; 181 however, FAGR had highest relative seed fall (seeds leaf ${ }^{-1}$ ) at 700m in CAL (Tables 3 and 4). 182 Relative seed fall of ACSA was greater at REF1 than the other sites (Table 3). Elevation effects 183 were stronger for ACSA than for FAGR; however, both species had a significant elevation 184 interaction term (Tables 3 and 4). At both REF sites, ACSA relative seed fall decreased 185 significantly at 700m; however, on CAL the decrease was not significant (Tables 3 and 4). The 186 largest elevation effect for FAGR was higher relative seed fall on CAL at 700m (Table 3).

\section{Discussion}

Both species displayed masting (Kelly 1994) (Fig. 1; Table 3). The coincidence of mast 190 years (4 years: 2000, 2002, 2006, and 2011) and significant correlation between species 191 suggested that the two species were responding, at least in part, to a common cue. In particular, 192 application of the $\Delta \mathrm{T}$ model indicated that masting in both species was probably responding 
193 primarily to the difference in temperature between the previous two years as a proximate cue

194 (Kelly et al. 2013). In contrast to some previous reports (Long et al. 2011; Piovesan and Adams

195 2001), we found no evidence of precipitation or drought effects on masting of either species.

196 However, soil characteristics and bedrock depth are particularly important for delineating

197 drought conditions in New Hampshire and indexes such as the PDSI based mainly on

198 precipitation perform poorly (Davis and Stampone 2014). The predictive power of the $\Delta \mathrm{T}$ model

199 for FAGR could allow wildlife managers to better predict seed crops for wildlife (Jensen et al.

200 2012). Moreover, maple sugar producers could use the $\Delta T$ model for ACSA to predict sap

201 quality, given the reported relationship to mast years (Rapp and Crone 2015).

202

The role of internal controls and resource balance in regulating masting of these species

203 was suggested by the significance of previous-year seed fall as a predictor; particularly for

204 FAGR (Table 2). Previous studies have also indicated a strong effect of previous year seed fall in

205 regulating masting of Fagus spp. (Jakubas et al. 2005; Wagner et al. 2010), but the actual

206 resource that contributes to this apparent constraint on seed production is not known. This effect

207 of previous seed production has not been quantified previously for ACSA, but indications of

208 resource constraints were suggested by reduced maple sugar production in the year following

209 masting (Rapp and Crone 2015). For ACSA, resource allocation to seeds in the previous year is

210 complicated by an unknown and variable proportion of the seeds being unfilled perhaps

211 contributing to the weakness of the relationship found here.

212 Because the magnitude and frequency of masting may be reduced in the stressful

213 environment near a species' range limits (Kelly and Sork 2002), we expected seed fall and

214 masting to vary with elevation. In fact, we observed contrasting patterns of seed fall in relation to

215 elevation for the two species. Relative seed production was lower at the highest elevation at both 
216 reference sites for ACSA, but at none of the reference sites for FAGR. Thus, there was support

217 for decreased seed production near the elevation limits for ACSA, but not for FAGR. Moreover,

218 there were several other intriguing trends with elevation, which should be further considered for

219 biological significance. Frequency of mast years and synchronicity between sites both decreased

220 at high elevation (Table 3). At high elevations sites, the occurrence of moderate seed years was

221 lessened for ACSA and enhanced for FAGR, as reflected by differences in their $\mathrm{CV}_{\mathrm{s}}$ values

222 (Table 3; Fig. S1).

Previous plot-level studies in Pennsylvania (Long et al. 1997, 2011) and HBEF (Halman

224 et al. 2013) indicated that seed production by ACSA was stimulated by Ca additions, but we

225 observed limited effects of Ca treatment on seed production parameters in this highly Ca-

226 sensitive species (Schaberg et al. 2006). The difference between our study and the Pennsylvania

227 studies may reflect treatment intensity as about five times more Ca was added than in the present

228 study. However, Ca addition rate in the plot-level study at HBEF (Halman et al. 2013) was

229 comparable to our watershed-level application. Thus, local site-level factors also appear to

230 influence the response of ACSA seed production to mitigation of soil Ca depletion.

231 The Ca addition ameliorated elevation effects on seed production for both species (i.e.

232 causing significant interaction term; Table 4), but to a much greater extent for FAGR (Table 3).

233 Some weak evidence for amelioration of seed production limits at high elevation due to Ca

234 addition was observed for ACSA, while relative seed production for FAGR was highest at 700m

235 and lowest at 500m on CAL; the reverse of the expected pattern (Kelly and Sork 2002; Piovesan

236 and Adams 2001), The stronger Ca effect on FAGR seed fall at high elevation was surprising

237 given the many studies showing ACSA to be more sensitive to Ca amendments than FAGR, but 
238 in agreement with greater overall forest response from the Ca addition at higher elevation on

239 CAL reported previously (Battles et al. 2014; Minocha et al. 2010).

The synchronicity of mean seed production at three sites distributed over several $\mathrm{km}$ in

241 the HBEF was moderate to high (Table 2; Koenig et al. 2003). Several of our mast years also

242 coincided with those reported as high seed years from other sites in the Northeast (Table S1).

243 The comparison of predicted versus actual seed production (Fig. 2) highlighted one apparently

244 failed mast year. For ACSA, the year 2013 was predicted to be a mast year; this year also

245 exhibited high between-site variability in seed production in Vermont (Rapp and Crone 2015).

246 Overall, the model predictions were fairly close to actual seed production patterns and show

247 promise for forecasting seed production and related variables for these two important tree

248 species.

250 Acknowledgements

251

252

253

254

255

256

257

258

259

Cindy Wood was critical in maintaining the high quality of the seed production data from 1993-2013. Amey Bailey (USFS) maintains the long-term weather data and provided 2015 temperature and precipitation data not currently available in the weblink. The comments of two anonymous reviewers greatly improved the manuscript. This project was funded by grants from the National Science Foundation (NSF) and is a contribution to the Hubbard Brook Ecosystem Study. Hubbard Brook is part of the Long-term Ecological Research (LTER) network, which is supported by NSF. The HBEF is operated and maintained by the USDA Forest Service, Northern Research Station, Newtown Square, PA, U.S. 
260

261

262

263

264

265

266

267

268

269

270

271

272

273

274

275

276

277

278

279

\section{References}

Bailey, A.S., Hornbeck, J.W., Campbell, J.L., and Eagar, C. 2003. Hydrometeorological database for Hubbard Brook Experimental Forest: 1955-2000. Gen. Tech. Rep. NE-305. Newtown Square, PA: U.S. Department of Agriculture, Forest Service, Northeastern Research Station. 36p.

Battles, J.J., Fahey, T.J., Driscoll, C.T., Blum, J.D., and Johnson, C.E. 2014. Restoring soil Calcium reverses forest decline. Environmental Science and Technology Letters 1: 1519. DOI: $10.1021 / \mathrm{ez} 400033 \mathrm{~d}$.

Bergeron, P., Reale, D., Humphries, M.M., and Garant, D. 2011. Anticipation and tracking of pulsed resources drive population dynamics in eastern chipmunks. Ecology 92: 20272034.

Cleavitt, N.L., Fairbairn, M., and Fahey, T.J. 2008. Growth and survivorship of American beech (Fagus grandifolia Ehrh.) seedlings in a northern hardwood forest following a mast event. J Torrey Bot. Soc. 135: 328-345.

Cleavitt, N.L., Fahey, T.J., and Battles, J.J. 2011. Regeneration ecology of sugar maple (Acer saccharum): seedling survival in relation to nutrition, site factors, and damage by insects and pathogens. Can. J. For. Res. 41: 235-244.

Cleavitt, N.L., Battles, J.J., Fahey, T.J., and Blum, J.D. 2014. Determinants of survival over seven years for a natural cohort of sugar maple seedlings in a northern hardwood forest. Can. J. For. Res.44: 1112-1121. 
280 281

282

283

284

285

286

287

288

289

290

291

292

293

294

295

296

297

298

299

300

301

Crone, E.E., and Rapp, J.M. 2014. Resource depletion, pollen coupling, and the ecology of mast seeding. Annals of the New York Academy of Sciences 1322: 21-34.

Davis, J. M., and Stampone, M. 2014. Analysis of drought conditions in New Hampshire. Online resource: des.nh.gov.

Fahey, T.J., Siccama, T.G., Driscoll, C.T., Likens, G.E., Campbell, J.L., Johnson, C.E., Battles, J.J., Aber, J.D., Cole, J.J., Fisk, M.C., Groffman, P.M., Hamburg, S.P., Holmes, R.T., Schwarz, P.A., and Yanai, R.D.. 2005. The biogeochemistry of carbon at Hubbard Brook. Biogeochemistry 75: 109-176. doi:10.1007/s10533-004-6321-y.

Halman, J.M., Schaberg, P.A., Hawley, G.J., Pardo, L.H., and Fahey, T.J. 2013. Calcium and aluminum impacts on sugar maple physiology in a northern hardwood forest. Tree Phys. 33: $1242-1251$.

Jakubas, W.J., McLaughlin, C.R., Jensen, P.G., and McNulty, S.A. 2005. Alternate year beechnut production and its influence on bear and marten populations. Pp: 79-87 In: Evans, C.A., Lucas, J.A., and Twery, M.J. 2005. Beech Bark Disease: Proceedings of the Beech Bark Disease Symposium. Gen. Tech. Rep. NE-331. Newtown Square PA, US. Department of Agriculture Forest Service, Northern Research Station. 149 p.

Janzen, D.H. 1971. Seed predation by animals. Ann. Rev. Ecol. Syst. 2: 465-492.

Jansen, P.A., Bongers, F., and Hemerik, L. 2004. Seed mass and mast seeding enhance dispersal by scatter-hoarding rodent. Ecological Monographs 74: 569-589.

Jensen, P.G., Demers, C.L., McNulty, S.A., Jakubas, W.J., and Humphries, M.M. 2012. Marten and Fisher Responses to Fluctuations in Prey Populations and Mast Crops in the Northern Hardwood Forest. Journal of Wildlife Management 76: 489-502. 
302

303

304

305

306

307

308

309

310

311

312

313

314

315

316

317

318

319

320

321

322

323

$\mathrm{JMP}^{\circledR}$, Version 11 for Windows. SAS Institute Inc., Cary, NC, 1989-2007.

Johnson, C.E., Driscoll, C.T., Blum, J.D., Fahey, T.J., and Battles, J.J. 2014. Soil Chemical Dynamics after Calcium Silicate Addition to a Northern Hardwood Forest. Soil Sci. Soc. Am. J. 78: 1458-1468. DOI: 10.2136/sssaj2014.03.0114.

Juice, S.M., Fahey, T.J., Siccama, T.G., Driscoll, C.T., Denny, E.G., Eagar, C., Cleavitt, N.L., Minocha, R., and Richardson, A.D. 2006. Response of sugar maple to calcium addition to northern hardwood forest at Hubbard Brook, NH. Ecology 87: 1267-1280.

Kelly, D. 1994. The evolutionary ecology of mast seeding. TREE 9: 465-470.

Kelly, D., Geldenhuis, J.A., Holland, E.P., Plank, M.J., Brockie, R.E., Cowan, P.E., Harper, G.A., Lee, W.G., Maitland, M.J., Mark, A.F., Mills, J.A., Wilson, P.R., and Byrom, A.E. 2013. Of mast and mean: differential-temperature cue makes mast seeding insensitive to climate change. Ecol. Lett. 169: 90-98. doi: 10.1111/ele.12020.

Kelly, D., and Sork, V.I. 2002. Mast seeding in perennial plants: why, how, where? Ann. Rev. Ecol. Syst.33: 427-447.

Koenig, W.D., Kelly, D., Sork, V.L., Duncan, R.P., Elkinton, J.S., Peltonen, M.S., and Westfall, R.D. 2003. Dissecting components of population-level variation in seed production and the evolution of masting behavior. Oikos 102: 581-591.

Koenig, W.D., Alejano, R., Carbonero, M.D., Fernandez-Rebollo, P., Knops, J.M.H., Maranon, T., Padilla-Diaz, C.M., Pearse, I.S., Perez-Ramos, I.M., Vazquez-Pique, J., and Pesendorfer, M.B. 2016. Is the relationship between mast-seeding and weather in oaks related to their life-history or phylogeny? Ecology 97: 2603-2615. Doi: 10.1002/ecy.1490. 
LaMontagne, J.M., and Boutin, S. 2007. Local-scale synchrony and variability in mast seed production patterns of Picea glauca. J. Ecol. 95: 991-1000.

LaMontagne, J.M., and Boutin, S. 2009. Quantitative methods for defining mast-seeding years across species and studies. J. Veg. Sci. 20: 745-753.

Likens, G.E., and Bormann, F.H. 1995. Biogeochemistry of a Forested Ecosystem. Second Edition, Springer-Verlag New York Inc.

Long, R.P., Horsley, S.B., and Lilja, P.R. 1997. Impact of forest liming on growth and crown vigor of sugar maple and associated hardwoods. Can. J. For. Res. 27: 1560.1573

Long, R.P., Horsley, S.B., and Hall, T.J. 2011. Long-term impact of liming on growth and vigor of northern hardwoods. Can. J. For. Res. 41: 1295-1307. doi:10.1139/X11-049.

Minocha, R., Long, S., Thangavel, P., Minocha, S.C., Eagar, C., and Driscoll, C.T. 2010. Elevation dependent sensitivity of northern hardwoods to Ca addition at Hubbard Brook Experimental Forest, NH, USA. For. Ecol. Manage. 260:2115-2124.

Ostfeld, R., and F. Keesing. 2000. Pulsed resources and community dynamics in terrestrial ecosystems. TREE 15: 232-237.

Pearse, I.S., Koenig, W.D., and Kelly, D. 2016. Mechanisms of mast seeding: resources, weather cues, and selection. New Phytol. 212: 546-562. doi:10.1111/nph.14114.

Peters, S.C., Blum, J.D., Driscoll, C.T., and Likens, G.E. 2004. Dissolution of wollastonite during the experimental manipulation of Hubbard Brook Watershed 1. Biogeochem. 67:309-329. doi:10.1023/B:BIOG.0000015787.44175.3f.

Piovesan, G., and Adams, J.M. 2001. Masting behaviour in beech: linking reproduction and climatic variation. Can. J. Bot. 79: 1039-1047. 
346 Rapp, J.M., and Crone, E.E. 2015. Maple syrup production declines following masting. For. Ecol. Manage. 335: 249-254. doi: 10.1016/j.foreco.2014.09.041.

348 Schaberg, P.G., Tilley, J.W., Hawley, G.J., DeHayes, D.H., and Bailey, S.W. 2006. Associations 349 of calcium and aluminum with the growth and health of sugar maple trees in Vermont. For. Ecol. Manage. 223: 159-169. doi:10.1016/j.foreco.2005.10.067.

van Doorn, N.S., Battles, J.J., Fahey, T.J., Siccama, T.G., and Schwarz, P.A. 2011. Links between biomass and tree demography in a northern hardwood forest: a decade of stability and change in Hubbard Brook Valley, New Hampshire. Can. J. For. Res. 41: $1369-1379$.

Wagner, S., Collet, C., Madsen, P., Nakashizuka, T., Nyland, R.D., and Sagheb-Talebi, K. 2010. Beech regeneration research: From ecological to silvicultural aspects. Forest Ecol. Manage. doi:10.1016/j.foreco.2010.02.029. 
Table 1. Descriptions of seed trap collection sites in Hubbard Brook Experimental Forest, NH. The species data is meant to summarize abundance of species in the collection sites: Leaf (percent of leaves that are target species out of all leaves over time in the collections); Rel. abund (the relative abundance by tree density in the collection site). Seed data are means (1SE) and are given as seeds $\mathrm{m}^{-2}$.

\begin{tabular}{cccccccc}
\hline & \multicolumn{3}{c}{ Acer saccharum (ACSA) } & \multicolumn{3}{c}{ Fagus grandifolia (FAGR) } \\
& Elev & Leaf & Rel. & Seeds & Leaf & Rel. & Seeds \\
Sites & class & $(\%)$ & abund & $\mathrm{m}^{-2}$ & $(\%)$ & abund & $\mathrm{m}^{-2}$ \\
& & & $(\%)$ & & & $(\%)$ & \\
\hline REF1 & $500 \mathrm{~m}$ & 19.8 & 39.5 & $38(4.5)$ & 29.6 & 30.2 & $19(4.0)$ \\
(1993-present; 12 traps per & $600 \mathrm{~m}$ & 72.7 & 82.6 & $194(22)$ & 27.3 & 13.0 & $16(4.1)$ \\
elevation) & $700 \mathrm{~m}$ & 29.8 & 41.3 & $22(3.1)$ & 27.6 & 21.7 & $5.7(1.0)$ \\
\hline REF2 & $500 \mathrm{~m}$ & 41.5 & 20.0 & $49(6.2)$ & 27.9 & 72.0 & $20(3.5)$ \\
(1994, 1995, 1997-present; 10 & $600 \mathrm{~m}$ & 39.1 & 35.3 & $50(7.5)$ & 32.6 & 47.1 & $14(3.5)$ \\
traps per elevation) & $700 \mathrm{~m}$ & 1.9 & 3.1 & $0.8(0.3)$ & 68.3 & 71.9 & $33(4.1)$ \\
\hline CAL & $500 \mathrm{~m}$ & 50.8 & 62.3 & $65(7.4)$ & 18.2 & 15.6 & $3.8(0.7)$ \\
(1998-present; 12 traps per & $600 \mathrm{~m}$ & 35.0 & 43.9 & $29(3.7)$ & 50.1 & 49.5 & $19(2.5)$ \\
elevation) & $700 \mathrm{~m}$ & 39.2 & 16.1 & $21(3.4)$ & 23.9 & 19.5 & $23(3.6)$ \\
\hline
\end{tabular}


Table 2. Comparisons of generalized linear models predicting seed production (seeds $\mathrm{m}^{-2}$ ) in sugar maple (ACSA) and American beech (FAGR) over 19-yrs (1998-2016). Significance of the deviance reduction was evaluated by likelihood ratio chi square $\left(\mathrm{X}^{2}\right)$ test: ${ }^{*} \mathrm{p}<0.05 ; * * \mathrm{p}<0.01$; $* * * \mathrm{p}<0.001$. Akaike's information corrected criterion $\left(\mathrm{AIC}_{\mathrm{c}}\right)$ used to compare fit between models, where the model with the lowest was set to "zero" and all other models compared by the difference in model $\mathrm{AIC}_{\mathrm{c}}\left(\Delta \mathrm{AIC}_{\mathrm{c}}\right)$. The best model for each species is in bold. Model abbreviations: $\Delta \mathrm{T}$ (difference in summer temperatures for year ${ }^{-1}$ and year ${ }^{-2}$ ); $\mathrm{Ppt}$ (growing season precipitation); $\Delta \mathrm{Ppt}$ (difference in growing season precipitation for year ${ }^{-1}$ and year ${ }^{-2}$ ); $\mathrm{T}$ (temperature); summer (sum of the mean temperatures for June-August).

\begin{tabular}{|c|c|c|c|c|}
\hline \multirow[b]{3}{*}{ Model } & \multicolumn{2}{|c|}{ ACSA } & \multicolumn{2}{|c|}{ FAGR } \\
\hline & Likelihood & & Likelihood & \\
\hline & ratio $X^{2}$ & $\Delta \mathrm{AIC}_{\mathrm{c}}$ & ratio $X^{2}$ & $\Delta \mathrm{AIC}_{\mathrm{c}}$ \\
\hline$\Delta \mathrm{T}$ & $22.9 * * *$ & $\mathbf{0}$ & $18.2 * * *$ & 1.1 \\
\hline$\Delta \mathrm{T}+$ previous seed & $22.9 * * *$ & 3.2 & $22.9 * * *$ & $\mathbf{0}$ \\
\hline Previous seed & $9.4 * *$ & 13.6 & $16.9 * * *$ & 2.4 \\
\hline Summer T $\mathrm{yr}^{-2}$ & $7.5 * *$ & 15.4 & $7.5 * *$ & 11.8 \\
\hline July $\mathrm{T} \mathrm{yr}^{-2}$ & $8.1^{* *}$ & 17.0 & $5.8^{*}$ & 17.0 \\
\hline Summer $\mathrm{T} \mathrm{yr}^{-1}$ & $5.7^{*}$ & 17.2 & $4.1^{*}$ & 18.7 \\
\hline July T yr ${ }^{-1}$ & 1.9 & 21.1 & 0.5 & 18.8 \\
\hline Ppt $y^{-1}$ & 0.2 & 22.7 & 0.1 & 19.2 \\
\hline$\Delta \mathrm{Ppt}$ & 0.2 & 22.8 & 0.1 & 19.2 \\
\hline
\end{tabular}


Table 3. Site-level comparisons of seed production by sugar maple (ACSA) and American beech (FAGR) in Hubbard Brook Experimental Forest, NH. The average Spearman correlation to all other sites and the coincidence of mast years were used to assess synchronicity and frequency of masting. Mast years for sites are delineated in Figure S1. The coefficient of variation (CV) and relative seed production (Rel. seeds: seeds per100 leaves in the same collectors) compare the magnitude of masting. Tukey-Kramer post-hoc subsets for relative seed production are given by letter superscripts within the column $(\alpha=0.05)$.

\begin{tabular}{|c|c|c|c|c|c|c|c|c|c|}
\hline \multirow[b]{2}{*}{ Site } & \multirow[b]{2}{*}{$\begin{array}{l}\text { Elev } \\
\text { class }\end{array}$} & \multicolumn{4}{|c|}{ ACSA } & \multicolumn{4}{|c|}{ FAGR } \\
\hline & & $\begin{array}{l}\text { Ave. } \\
\text { Corr. }\end{array}$ & Mast years & $\mathrm{CV}$ & $\begin{array}{c}\text { Rel. seeds } \\
\text { (per } 100 \\
\text { lvs) }\end{array}$ & $\begin{array}{l}\text { Ave. } \\
\text { Corr. }\end{array}$ & Mast years & $\mathrm{CV}$ & $\begin{array}{c}\text { Rel. seeds } \\
\text { (per } 100 \\
\text { lvs) }\end{array}$ \\
\hline \multirow{3}{*}{ REF1 } & $500 \mathrm{~m}$ & 0.844 & $\begin{array}{l}\text { 1994, 1996, 1998, 2000, } \\
2002,2006,2011\end{array}$ & 1.33 & $15.3(2.1)^{\mathrm{a}}$ & 0.767 & $\begin{array}{l}\text { 1996, 2002, 2006, 2011, } \\
2013,2015\end{array}$ & 1.30 & $2.5(0.4)^{\mathrm{bc}}$ \\
\hline & $600 \mathrm{~m}$ & 0.862 & $\begin{array}{l}\text { 1994, 1996, 2002, 2006, } \\
2011\end{array}$ & 1.46 & $14.0(1.6)^{\mathrm{a}}$ & 0.782 & 2000, 2002, 2006, 2011 & 1.42 & $2.1(0.5)^{b c}$ \\
\hline & $700 \mathrm{~m}$ & 0.806 & $\begin{array}{l}\text { 1994, 1996, 2002, 2006, } \\
2011\end{array}$ & 1.57 & $4.6(0.7)^{\mathrm{bc}}$ & 0.751 & $\begin{array}{l}\text { 1995, 1996, 2006, 2011, } \\
2013\end{array}$ & 1.04 & $0.9(0.1)^{\mathrm{c}}$ \\
\hline \multirow{3}{*}{ REF2 } & $500 \mathrm{~m}$ & 0.882 & $\begin{array}{l}\text { 1994, 1998, 2000, 2002, } \\
2006,2011\end{array}$ & 1.42 & $8.9(1.3)^{\mathrm{ab}}$ & 0.758 & $\begin{array}{l}2000,2002,2006,2011, \\
2013\end{array}$ & 1.24 & $3.0(0.5)^{\mathrm{ab}}$ \\
\hline & $600 \mathrm{~m}$ & 0.857 & $1994,2000,2002,2006$ & 1.74 & $7.4(1.1)^{\mathrm{b}}$ & 0.739 & $2000,2002,2006,2013$ & 1.80 & $1.9(0.4)^{\mathrm{c}}$ \\
\hline & $700 \mathrm{~m}$ & 0.621 & $1994,2000,2011$ & 2.33 & $1.6(1.0)^{\mathrm{c}}$ & 0.685 & $2002,2011,2015$ & 0.87 & $2.9(0.3)^{b}$ \\
\hline \multirow{3}{*}{ CAL } & $500 \mathrm{~m}$ & 0.846 & $2002,2006,2011$ & 1.59 & $7.6(1.2)^{b}$ & 0.750 & $\begin{array}{l}1998,2000,2002,2006 \\
2011,2013,2015\end{array}$ & 1.15 & $0.9(0.2)^{\mathrm{c}}$ \\
\hline & \multicolumn{7}{|c|}{ 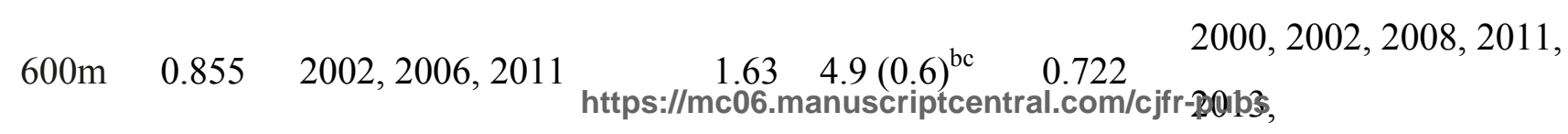 } & 1.20 & $1.9(0.2)^{\mathrm{bc}}$ \\
\hline & $700 \mathrm{~m}$ & 0.838 & $2006,2011,2013$ & 1.73 & $4.8(1.3)^{\mathrm{bc}}$ & 0.670 & $2006,2011,2013,2015$ & 1.07 & $4.5(0.7)^{\mathrm{a}}$ \\
\hline
\end{tabular}


Table 4. Summary of mixed models for between site comparisons of seed production and relative seed production (seed leaf ${ }^{-1}$ ) in sugar maple (ACSA) and American beech (FAGR) from three sites in HBEF, NH for 19-yrs (1998-2016). Significance of the F ratio: ${ }^{*} \mathrm{p}<0.05$; ${ }^{*} \mathrm{p}<$ $0.01 ; * * * p<0.001$. Post-hoc separation is presented in Table 3.

\begin{tabular}{|c|c|c|c|c|}
\hline Fixed effect: & & Site & Elevation & Site $\mathrm{x}$ Elevation \\
\hline Test variable & df den & df 2 & df 2 & df 4 \\
\hline ACSA seeds leaf $^{-1}$ & 751 & $16.5 * * *$ & $6.49 * *$ & $5.15 * *$ \\
\hline FAGR seeds leaf ${ }^{-1}$ & 621 & 1.97 & $6.45^{* *}$ & $11.2 * * *$ \\
\hline
\end{tabular}




\section{Figure Legends}

Figure 1. Seed production for sugar maple (ACSA) and American beech (FAGR) at Hubbard Brook Experimental Forest, NH from 1994-2016: A. Bars show the annual means $( \pm$ 1SE) for all reference site collectors $(\mathrm{N}=66)$ and asterisks denote mast years. The longterm mean is shown by a solid line. B. the standardized deviation of annual seed production from the long-term means (ASD) and coefficient of variation (CV). Years with ASD values above the minimum standardized deviate (dotted line) were considered mast years.

Figure 2. Actual (heavy solid line) and predicted logarithm of seed production for sugar maple (ACSA) and American beech (FAGR) at Hubbard Brook Experimental Forest, NH from 1998-2016. For both species the predicted values from model: $\Delta \mathrm{T}+$ previous seed production are the light dashed lines. For ACSA, the light gray line is $\Delta \mathrm{T}$ alone and for FAGR light gray line represents the previous seed production alone. See Table 3 for model comparison and statistics of fit. 

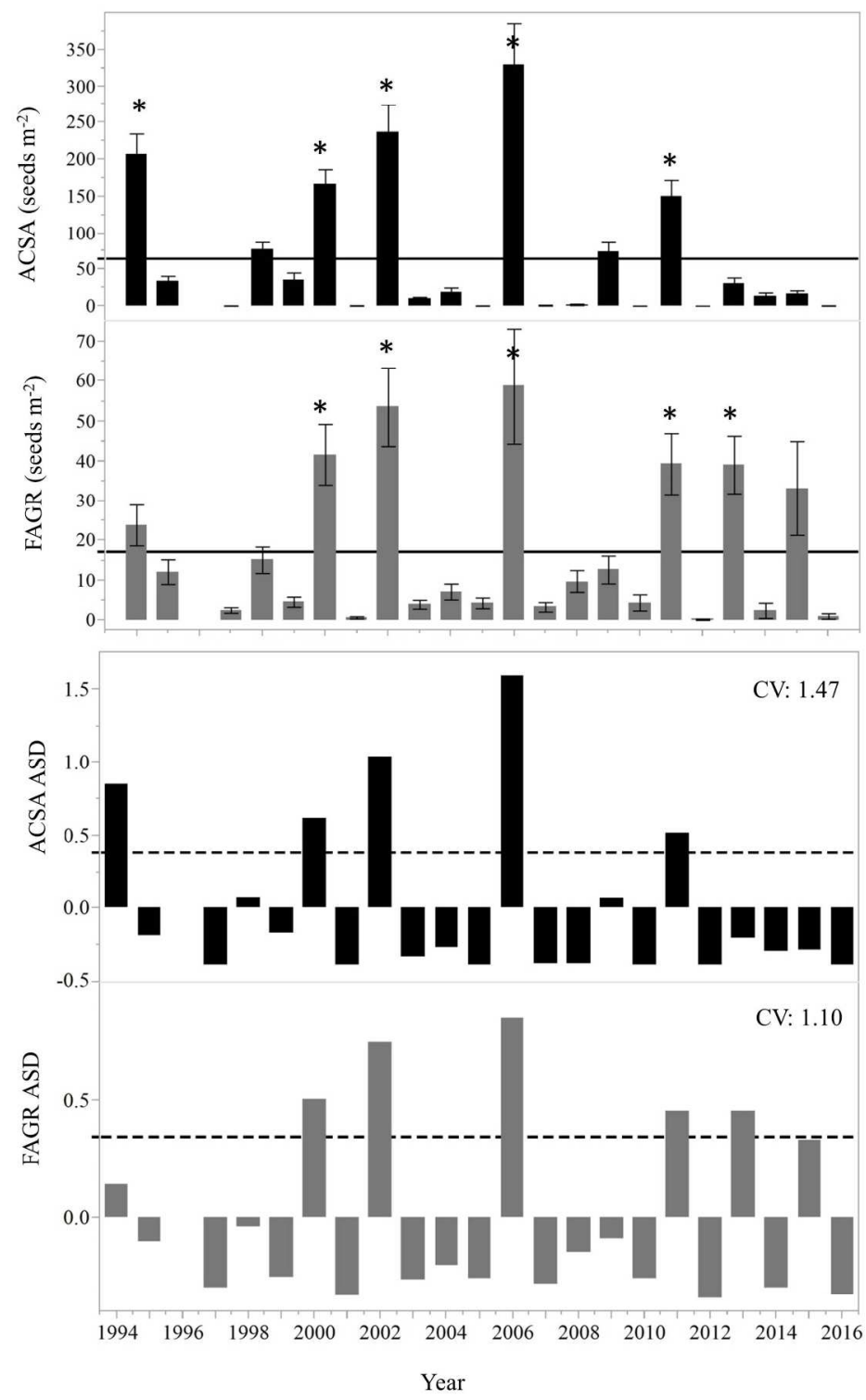

Figure 1. Seed production for sugar maple (ACSA) and American beech (FAGR) at Hubbard Brook Experimental Forest, NH from 1994-2016: A. Bars show the annual means ( \pm 1SE) for all reference site collectors $(\mathrm{N}=66)$ and asterisks denote mast years. The long-term mean is shown by a solid line. $B$. the standardized deviation of annual seed production from the long-term means (ASD) and coefficient of variation (CV). Years with ASD values above the minimum standardized deviate (dotted line) were considered mast years.

$254 \times 338 \mathrm{~mm}$ ( $300 \times 300$ DPI) 


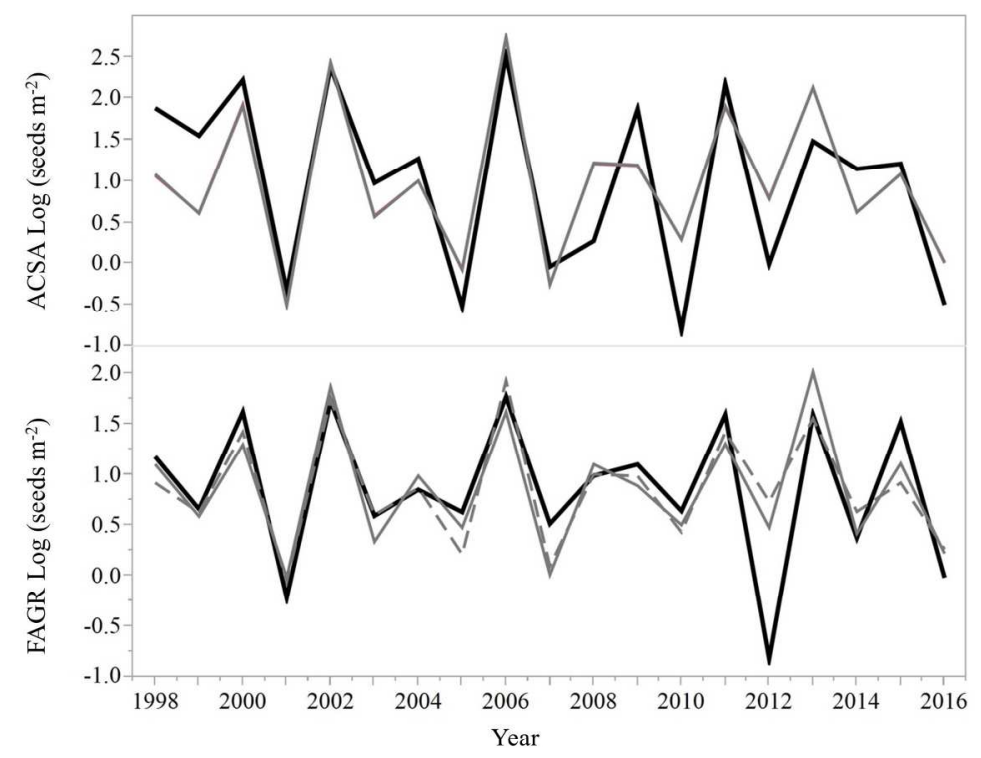

Figure 2. Actual (heavy solid line) and predicted logarithm of seed production for sugar maple (ACSA) and American beech (FAGR) at Hubbard Brook Experimental Forest, NH from 1998-2016. For both species the predicted values from model: $\Delta T+$ previous seed production are the light dashed lines. For ACSA, the light gray line is $\Delta T$ alone and for FAGR light gray line represents the previous seed production alone. See Table 3 for model comparison and statistics of fit.

$254 \times 338 \mathrm{~mm}(300 \times 300$ DPI $)$ 
Table S1. Summary of studies reporting seed production data for sugar maple (ACSA) and American beech (FAGR) from 1959 through the present in the Northeast portion of their range.

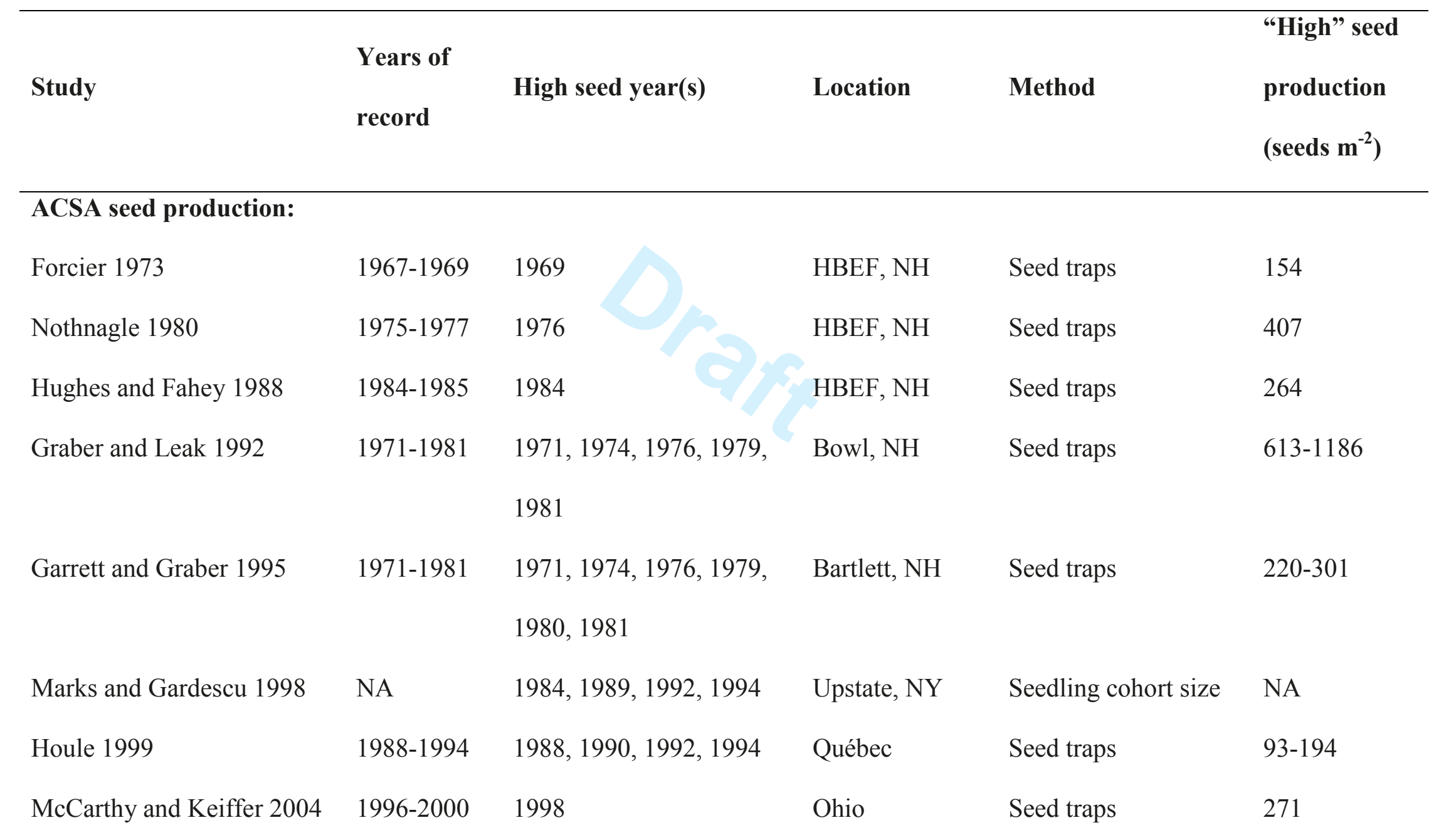




\begin{tabular}{|c|c|c|c|c|c|}
\hline Gardescu 2003 & NA & 1984,1988 & Upstate, NY & Seedling cohort size & NA \\
\hline Long et al. 2011 & $1987-2008$ & $\begin{array}{l}1989,1992,2000,2003, \\
2006\end{array}$ & Pennsylvania & Index 0-7 & NA \\
\hline Graignic et al. 2014 & NA & $1996,2002,2003,2006$ & Québec & $\begin{array}{l}\text { Age structure of } \\
\text { seedlings }\end{array}$ & NA \\
\hline Rapp and Crone 2015 & $1998-2013$ & $1998,2000,2006,2011$ & Vermont & $\begin{array}{l}\text { Proportion of trees } \\
\text { with seeds }\end{array}$ & NA \\
\hline This study & $1993-2016$ & $\begin{array}{l}\text { 1994, 1996, 2000, 2002, } \\
2006,2011\end{array}$ & HBEF, NH & Seed traps & $140-253$ \\
\hline \multicolumn{6}{|l|}{ FAGR seed production: } \\
\hline Gysel 1971 & $1959-1968$ & 1960,1964 & Michigan & $\begin{array}{l}\text { Seed traps beneath } \\
\text { FAGR canopy }\end{array}$ & $275-474$ \\
\hline Forcier 1973 & $1968-1969$ & none & HBEF, NH & Seed traps & --- \\
\hline Nothnagle 1980 & $1975-1977$ & 1976 & HBEF, NH & Seed traps & 68 \\
\hline Hughes and Fahey 1988 & 1984-1985 & 1984 & $\mathrm{HBEF}, \mathrm{NH}$ & Seed traps & 59 \\
\hline Graber and Leak 1992 & 1971-1981 & 1971,1978 & Bowl, NH & Seed traps & 30,43 \\
\hline
\end{tabular}




\begin{tabular}{|c|c|c|c|c|c|}
\hline Leak and Graber 1993 & $1976-1981$ & $1976,1978,1980,1981$ & Bartlett, NH & Seed traps & $50-108$ \\
\hline McCarthy and Keiffer 2004 & $1996-2000$ & 1998,2000 & Ohio & Seed traps & $112-127$ \\
\hline Jakubas et al. 2005 & $1988-2003$ & $\begin{array}{l}\text { 1988, 1994, 1996, 1998, } \\
2000,2002\end{array}$ & $\begin{array}{l}\text { Adirondacks, } \\
\text { NY }\end{array}$ & Seed traps & $32-64$ \\
\hline Bergeron et al. 2011 & 2005-2009 & 2006,2008 & Québec & $\begin{array}{l}\text { Seed traps beneath } \\
\text { FAGR canopy }\end{array}$ & $135-246$ \\
\hline This study & $1993-2016$ & $\begin{array}{l}2000,2002,2006,2011, \\
2013\end{array}$ & $\mathrm{HBEF}, \mathrm{NH}$ & Seed traps & $39-56$ \\
\hline
\end{tabular}




\section{Additional references for Table S1.}

Forcier, L.K. 1973. Seedling pattern and population dynamics and the reproductive strategies of sugar maple, beech and yellow birch at Hubbard Brook. Ph.D. Thesis, Yale University, New Haven, CT.

Garrett, P.W., and Graber, R.E. 1995. Sugar maple seed production in northern New Hampshire. USDA FS RE-697.

Graber, R.E., and Leak, W.B. 1992. Seed fall in an old-growth northern hardwood forest. USDA Forest Service Research Paper NE-663.

Graignic, N; Tremblay, F., and Bergeron, Y. 2014. Geographical variation in reproductive capacity of sugar maple (Acer saccharum Marshall) northern peripheral populations. J Biogeography 41: 145-157. doi: 10.1111/jbi.12187

Gysel, L.W. 1971. A 10-Year Analysis of Beechnut Production and Use in Michigan. Journal of Wildlife Management 35: 516-519.

Houle, G. 1999. Mast seeding in Abies balsamea, Acer saccharum and Betula alleghaniensis in an old growth, cold temperate forest of north-eastern North America. Journal of Ecology 87: 413-422.

Hughes, J.W., and Fahey, T.J. 1988. Seed dispersal and colonization in a disturbed northern hardwood forest. Bull. Torrey Bot. Club 115:89-99.

Leak, W.B., and Graber, R.E. 1993. Six-year beechnut production in New Hampshire. Research Paper NE-677. USDA FS Northeastern Forest Station.

McCarthy, B.C., and Keiffer, C.H. 2004. Hardwood seed production in an old-growth mixed mesophytic forest in southeastern Ohio. In Yaussy, D.A., Hix, D.M., Long, R.P., Goebel, 
P.C., eds. 2004. Proceedings. 14th Central Hardwood Forest Conference. 2004 March 1619; Wooster, OH. Gen. Tech. Rep. NE-316. Newtown Square, PA: U.S. Department of Agriculture. Forest Service. Northeastern Research Station. 539 p.

Marks, P.L., and Gardescu, S. 1998. A Case Study of Sugar Maple (Acer saccharum) as a Forest Seedling Bank Species. Journal of the Torrey Botanical Society 125: 287-296.

Nothnagle, P. J. 1980. Mast fruiting and seed predation in a northern hardwoods forest. Ph.D. Thesis, Dartmouth College, Hanover, NH. 


\section{Legend}

Figure S1. The standardized deviation of annual seed production from the long-term means (ASD) for nine sites at Hubbard Brook Experimental Forest, NH. Years with ASD values above the minimum standardized deviate (dotted line) were considered mast years (as listed in Table 3). 


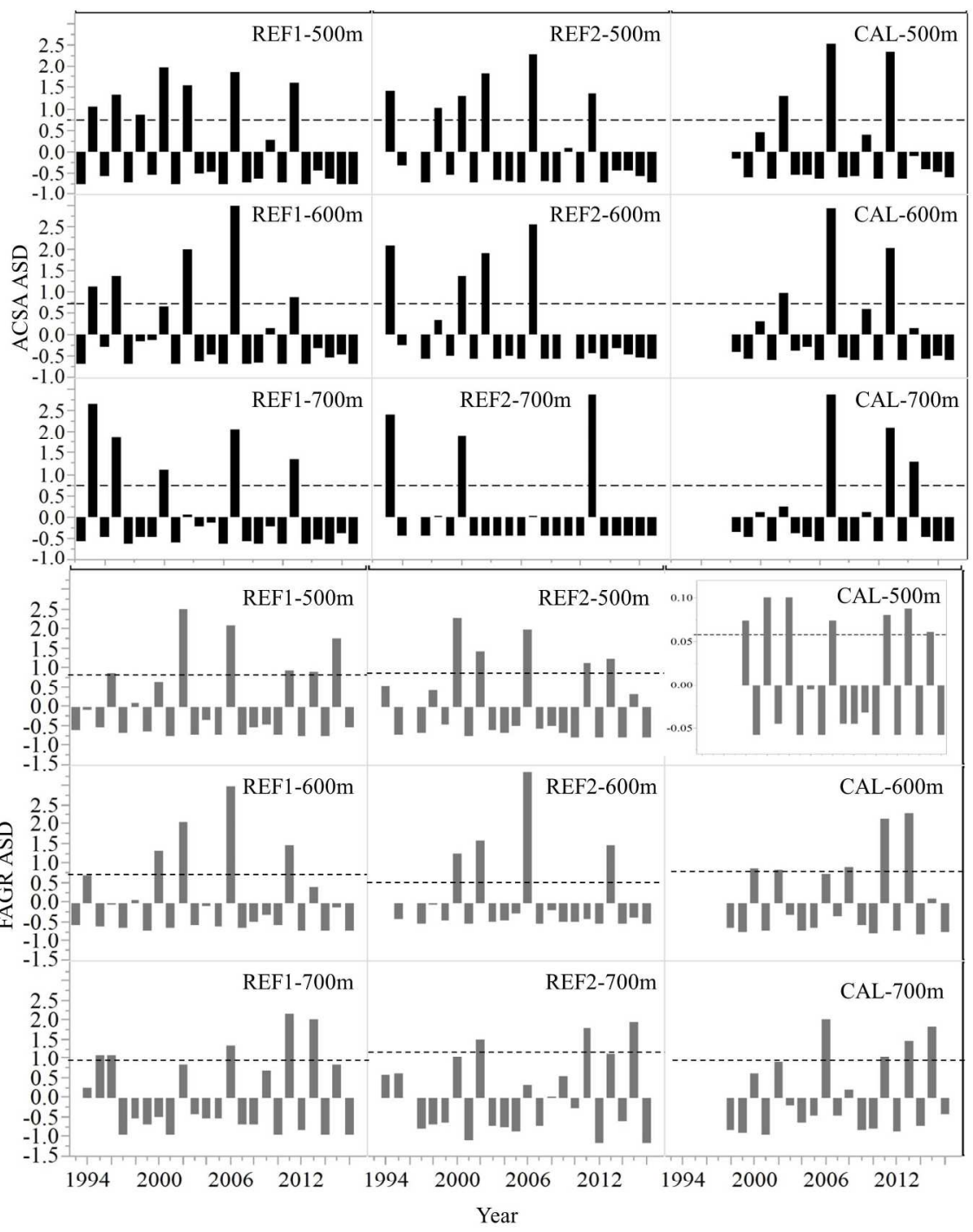

Figure S1. The standardized deviation of annual seed production from the long-term means (ASD) for nine sites at Hubbard Brook Experimental Forest, NH. Years with ASD values above the minimum standardized deviate (dotted line) were considered mast years (as listed in Table 3).

$254 \times 338 \mathrm{~mm}(300 \times 300 \mathrm{DPI})$ 